\title{
The Polish adaptation of the Five-Factor Obsessive-Compulsive Inventory - Short Form (FFOCI-SF): A preliminary study
}

\begin{abstract}
BACKGROUND
The Five-Factor Obsessive-Compulsive Inventory - Short Form (FFOCl-SF) is an instrument used to measure obsessive-compulsive personality disorder, which is one of the most widespread personality disorders. The FFOCI-SF is a shorter version of the FFOCI that was developed on the basis of the Five Factor Model of personality treated as a general framework for identifying different traits useful in describing maladaptive personality. This paper presents the psychometric parameters of the Polish adaptation of the FFOCl-SF.
\end{abstract}

\section{PARTICIPANTS AND PROCEDURE}

Our sample consisted of 328 respondents aged 18-75 (61\% women) from Poland. The voluntary and anonymous procedure consisted of completing inventories in a selfreported, paper-and-pencil way. The respondents received the FFOCI-SF, the Personal Inventory for DSM-5 (PID-5) and the Big Five Inventory-2 (BFI-2).

\section{RESULTS}

The findings suggest that there is acceptable internal consistency for most of the scales and some problems with the differentiation between some scales in factor analysis. Additionally, we present the hierarchical structure of the facets included in the instrument with two factors analogous to the metatraits of personality (Alpha and Beta). The criterion validity of the inventory was established by correlations on the one hand with Big Five traits $(\mathrm{BFI}-2)$ and on the other hand with another measure of the obsessivecompulsive personality disorder traits, namely appropriate scales from the Personality Inventory for DSM-5 (PID-5).

\section{CONCLUSIONS}

This study confirms that the FFOCI-SF is a valid measure for scientific purposes. In order to use it for diagnostic purposes, further research is suggested on clinical samples. The findings also suggest that the FFOCI-SF can be useful in exploring new solutions in structure of the obsessivecompulsive personality disorder facets.

\section{KEY WORDS}

Five-Factor Model; obsessive-compulsive personality disorder; traits; FFOCI-SF 


\section{BACKGROUND}

Personality disorders have always been a big challenge for psychological science and practice and there are many approaches in the literature to conceptualization of this kind of psychopathology (Fox, 2013; Magnavita, 2004; Livesley \& Larstone, 2018; Oldham, Skodol, \& Bender, 2014; Sperry, 2016; Widiger, 2012). Most conceptualizations regard personality disorders as a category of mental disorder, which begins in early childhood, is characterized by rigid and durable patterns of functioning in the field of cognition, affect, relationships or the interpersonal domain and causes individual suffering or handicap in social, professional or other important areas of life (Colman, 2009).

Obsessive-compulsive personality disorder (OCPD) is one of the personality disorders described in psychiatry and psychology. It has a long history within the clinical literature, including its roots in Freud's (1908/1959) "anal-retentive" type, which is composed of three traits: obstinacy, parsimony, and orderliness. The Diagnostic and Statistical Manual (DSM-5, American Psychiatric Association, 2013) gives a general definition of OCPD as "a pattern of preoccupation with orderliness, perfectionism, and control" and classifies OCPD as a Cluster $\mathrm{C}$ personality disorder. Cluster $\mathrm{C}$ is also known as the anxious, fearful cluster; avoidant personality disorder and dependent personality disorder are also classified as Cluster $\mathrm{C}$ personality disorders.

More specifically, OCPD can be described by a consistent pattern of preoccupation with orderliness, perfectionism, and a pervasive need for mental and interpersonal control which begins by early adulthood and is present in a variety of contexts. These features often lead to a loss of efficiency and flexibility and manifest in being preoccupied with details, rules, lists, order, organization, or schedules, an inability to complete a project or work because of high and strict standards, exclusion of leisure activities and friendships, inflexibility about matters of morality, ethics, or values, an inability to discard used or worthless objects, an unwillingness to delegate tasks or to cooperate with others, as well as showing rigidity and stubbornness. It is worthwhile to mention that OCPD needs to be differentiated from obsessive-compulsive disorder (OCD), which is designated an anxiety disorder and is characterized by real obsessions and compulsions (American Psychiatric Association, 2013).

The World Health Organization's ICD-10 refers to anankastic personality disorder (F60.5), which can be treated as a synonym of obsessive-compulsive personality disorder. ICD-10 describes anankastic personality disorder using the following diagnostic criteria: feelings of excessive doubt and caution, preoccupation with details, rules, lists, order, organization or schedule, perfectionism that interferes with task completion, excessive conscientiousness, scrupulousness, and undue preoccupation with productivity to the exclusion of pleasure and interpersonal relationships, excessive pedantry and adherence to social conventions, rigidity and stubbornness, unreasonable insistence by the patient that others submit to exactly his or her way of doing things, or unreasonable reluctance to allow others to do things, intrusion of insistent and unwelcome thoughts or impulses. The ICD-11 plans to include anankastic features such as perfectionism, an extreme need to control their own and others' behavior, and rigid adherence to rules consistent with the ICD-10 diagnosis of anankastic (obsessive-compulsive) personality disorder (Marras, Fineberg, \& Pallanti, 2016).

Presently, OCPD is estimated as the most often diagnosed personality disorder in the general population (Coid, Yang, Tyrer, Roberts, \& Ullrich, 2006; Costa, Samuels, Bagby, Daffin, \& Norton, 2005; Lindal \& Stefansson, 2009; Torgersen, 2009). According to the American Psychiatric Association (2013), the frequency of OCPD in the general population ranges from $2 \%$ to $8 \%$ and it is diagnosed about twice as often among males. This maladaptive style of functioning is related to many problems in everyday life. OCPD can be linked with other mental health disabilities such as eating disorders (Watson, Raykos, Street, Fursland, \& Nathan, 2011), depression and anxiety (Moser, Slane, Burt, \& Klump, 2012), and completed suicide in men (Schneider et al., 2006). The dysfunctional lifestyle among people with OCPD is very often at the expense of flexibility, openness and efficiency (Colman, 2009) as well as interpersonal relations (Cain, Ansell, Simpson, \& Pinto, 2015).

There have been many attempts to find a constellation of maladaptive personality traits in OCPD that can be measured and used as a basis for OCPD diagnosis (e.g., Baer, 1994; Grilo, 2004; Hummelen, Wilberg, Pedersen, \& Karterud, 2008). Some of these attempts have been based on the Five Factor Model (FFM) of personality by McCrae and Costa (2008) and involve examining maladaptive personality traits at the level of five basic domains (the Big Five) or 30 facets. The Five-Factor Obsessive-CompulsiveInventory (FFOCI; Samuel, Riddell, Lynam, Miller, \& Widiger, 2012) was developed in this way, and this strategy has also been used to construct measures for other psychopathologies, e.g., psychopathy (Decuyper, De Pauw, De Fruyt, De Bolle, \& De Clercq, 2009), and narcissism (Glover, Miller, Lynam, Crego, \& Widiger, 2012). Additionally, the theoretical and empirical analyses of the Big Five domains (e.g. Widiger \& Simonsen, 2005; cf. Strus et al., 2017) led to the proposal of the pathological Big Five domains that was included in section III of the DSM-5 (APA, 2013; Rowiński et al., 2019a). Within these domains, 25 more narrowly defined facets were differentiated that can be used to 
define specific categories of personality disorders. For example, in this model OCPD is characterized by Rigid Perfectionism and at least two of the following three traits: Intimacy Avoidance, Restricted Affectivity and Perseveration.

Finally, recent research has shown the usefulness of higher-order personality factors (i.e., Alpha/Stability and Beta/Plasticity of normal personality or Internalizing and Externalizing psychopathological tendencies; DeYoung, 2015; Markon, Krueger, \& Watson, 2005) in the analysis of various phenomena, an approach which may also be valuable for OCPD. The Circumplex of Personality Metatraits (CPM; Strus, Cieciuch, \& Rowiński, 2014; Strus \& Cieciuch, 2017; Zawadzki, 2016, 2017) seems to be especially useful as a matrix for many personality disorders as it differentiates the negative poles of Alpha and Beta as well as the two other metatraits Gamma and Delta.

The FFOCI (Samuel et al., 2012) is a measure of OCPD based on the Five Factor Model which was developed in the following way. Firstly, Lynam and Widiger (2001) interviewed experts focused on personality disorders, including OCPD, to describe a prototypic case of OCPD using all 30 facets of the FFM. Then, Widiger, Trull, Clarkin, Sanderson, and Costa (2002) used the DSM-IV-TR diagnostic criteria of OCPD based on clinicians' and researchers' descriptions (American Psychiatric Association, 2000) and coded them in terms of the FFM. Finally, 12 facets of the FFM were marked as being particularly pertinent for the evaluation of OCPD: Competence, Order, Dutifulness, Achievement striving, Self-discipline, Deliberation, Warmth, Excitement-seeking, Anxiety, (openness to) Feelings, Actions and Values. In the next step, an initial pool of 298 items was developed with about 22 items per scale: Perfectionism, Fastidiousness, Punctiliousness, Workaholism, Doggedness, Ruminative Deliberation, Detached Coldness, Risk Aversion, Excessive Worry, Constricted, Inflexibility, and Dogmatism. The collation of FFM facets and FFOCI subscales with sample items is presented in Table 1.

It should be noted that facets from different FFM domains can be found within the FFOCI scales (with the exception of Agreeableness). However - in accordance with the theoretical construct of OCPD (Samuel \& Widiger, 2011) - the FFOCI equivalents of Extraversion and Openness facets are in the opposite direction, and scales represented by the domain of Conscientiousness are dominant.

The internal consistency, convergent and discriminant validity with existing scales, as well as incremental validity over the NEO PI-R and existing assessments of OCPD have been examined for all 12 FFM OCPD trait scales (Samuel et al., 2012). Moreover, it is worthwhile to note that Crego, Samuel, and Widiger (2014) successfully compared the FFOCI conceptualization of OCPD with the DSM-5 (section III) dimensional trait model (i.e., facets of the pathological Big Five).
Finally, the Five-Factor Obsessive-Compulsive Inventory - Short Form (FFOCI-SF) was developed in order to provide researchers and clinicians with a brief measurement instrument. It contains 48 items selected from the 120 original FFOCI items on the basis of item response theory analyses. Research confirms that the nomological network and discriminant validity of the short form is comparable to the original long form of the measure (Griffin et al., 2018).

\section{CURRENT STUDY}

The main goal of the current study was to present the Polish adaptation of the FFOCI-SF. We expected (1) that the internal consistency of each FFOCI-SF scale would be acceptable as measured by Cronbach's $\alpha,(2)$ that the structural validity of the 12 scales would be confirmed in a confirmatory factor analysis, (3) to establish criterion validity, i.e., correlations between the relevant Big Five scales and the maladaptive facets of the pathological Big Five domains related to OCPD (according to the model from section III of DSM-5). The third hypothesis is presented in detail in Table 2.

Moreover, we explored the hierarchical structure of the 12 facets included in the FFOCI-SF. At the top level of the hierarchy, we expected to find two higher order factors similar to the higher-order factors above the Big Five (Cieciuch \& Strus, 2017). More specifically, we expected a factor analogous to the Alpha/Stability metatrait to group the Conscientiousness facets while a factor analogous to the Beta/Plasticity metatrait would group the Openness and Extraversion facets. All scales related to Conscientiousness measure high Conscientiousness while scales related to Openness and Extraversion are intended to measure low Openness and Extraversion. Therefore, we assumed that the metatraits of personality would form a useful matrix for interpreting the general factors of the FFOCI, and in particular, we expected to obtain one higher order factor analogous to the positive pole of Alpha-Plus (consisting of high Consciousness, Agreeableness and low Neuroticism) and a second higher order factor analogous to the negative pole of BetaMinus (consisting of low Openness and Extraversion) according to the CPM (Strus et al., 2014; Strus \& Cieciuch, 2017).

\section{PARTICIPANTS AND PROCEDURE}

\section{MEASURES}

Five-Factor Obsessive-Compulsive Inventory - Short Form. The FFOCI-SF (Griffin et al., 2018) is a 48-item self-report questionnaire constructed on the basis of the original 120-item FFOCI (Samuel et al., 2012).
The Polish adaptation of the FFOCI-SF 
Table 1

Obsessive-compulsive personality traits in FFM facets and FFOCI subscales

\begin{tabular}{|c|c|c|c|}
\hline & FFM facet & FFOCI subscale & Sample items in $\mathrm{FFOCI}$ \\
\hline \multicolumn{4}{|c|}{ Conscientiousness } \\
\hline $\mathrm{C} 1$ & Competence & Perfectionism & $\begin{array}{l}\text { "People often think I work too long and hard to } \\
\text { make things perfect" } \\
\text { "I like my work to be flawless and unblemished" }\end{array}$ \\
\hline $\mathrm{C} 2$ & Order & Fastidiousness & $\begin{array}{c}\text { "I probably spend more time than is needed } \\
\text { organizing and ordering things" } \\
\text { "I need to consider every little detail" }\end{array}$ \\
\hline $\mathrm{C} 3$ & Dutifulness & Punctiliousness & $\begin{array}{l}\text { "Some persons suggest I can be excessive in my } \\
\text { emphasis on being proper and moral" } \\
\text { "I have such a strong sense of duty that I some- } \\
\text { times become overcommitted" }\end{array}$ \\
\hline $\mathrm{C} 4$ & $\begin{array}{c}\text { Achievement } \\
\text { striving }\end{array}$ & Workaholism & $\begin{array}{c}\text { "My drive to succeed keeps me going when } \\
\text { others have stopped" } \\
\text { "I get so caught up in my work that I lose time } \\
\text { for other things" }\end{array}$ \\
\hline $\mathrm{C} 5$ & Self-discipline & Doggedness & $\begin{array}{l}\text { "I have a strong, perhaps at times even exces- } \\
\text { sive, single-minded determination" } \\
\text { "If I start something I work until it is complete" }\end{array}$ \\
\hline C6 & Deliberation & Ruminative & $\begin{array}{l}\text { "I think things over and over and over before } \\
\text { I make a decision" } \\
\text { "I often dwell on every possible thing that might } \\
\text { go wrong" }\end{array}$ \\
\hline
\end{tabular}

Extraversion

$\begin{array}{ccc}\text { E1 } & \text { Warmth (lack of) } & \begin{array}{c}\text { Detached } \\ \text { Coldness }\end{array} \\ \text { E5 } & \begin{array}{c}\text { Excitement-seeking } \\ \text { Risk-Aversion }\end{array} \\ \text { (lack of) } & \end{array}$

Openness to change
$\mathrm{O} 3$

O6 Values (lack of)

\section{Constricted}

Inflexibility
"I often come across as formal and reserved"

"Warmth and intimacy are not my strengths"

"I would always sacrifice fun and thrills for the security of my future"

"If it sounds exciting, I'd try anything once"

"I am a thinker, not a feeler"

"Strong emotions are not that important in my life"

"I like to keep to the 'tried and true' rather than try new things"

"I much prefer predictability than exploring the unknown"

"It troubles me how society is losing its strong moral core"

"I live my life by a set of tough, unyielding moral principles"

Neuroticism

N1

Anxiety
Excessive Worry
"I am often concerned, even nervous, about things going wrong" "I am a worrier"

Note. C - Conscientiousness, E - Extraversion, $\mathrm{O}$ - Openness; $\mathrm{N}$ - Neuroticism. The number following after the letter refers to the facet in NEO-PI-R. 
Table 2

Expected correlations between FFOCI scales and Big Five domains (measure by Big Five Inventory-2) and maladaptive facets (measure by Personality Inventory for DSM-5)

\begin{tabular}{|c|c|c|c|c|c|c|c|c|c|c|c|c|}
\hline & \multicolumn{12}{|c|}{ FFOCI scales } \\
\hline & $\mathrm{C} 1$ & $\mathrm{C} 2$ & $\mathrm{C} 3$ & $\mathrm{C} 4$ & $\mathrm{C} 5$ & $\mathrm{C} 6$ & $\mathrm{O} 3$ & $\mathrm{O} 4$ & O6 & E1 & E5 & N1 \\
\hline \multicolumn{13}{|l|}{ Big Five domains } \\
\hline Conscientiousness & + & + & + & + & + & + & & & & & & \\
\hline Openness & & & & & & & - & - & - & & & \\
\hline Extraversion & & & & & & & & & & - & - & \\
\hline Neuroticism & & & & & & & & & & & & + \\
\hline \multicolumn{13}{|l|}{ Agreeableness } \\
\hline \multicolumn{13}{|c|}{ Facets from the pathological Big Five (DSM-5) } \\
\hline Rigid Perfectionism & + & + & + & + & + & + & & & & & & \\
\hline Intimacy Avoidance & & & & & & & & & & + & + & \\
\hline Restricted Affectivity & & & & & & & & & & + & + & - \\
\hline Perseveration & & & & & & & & & & & & + \\
\hline
\end{tabular}

This research tool was designed to assess the 12 OCPD maladaptive variants of FFM facets. There are 12 scales and each of them consists of 4 items scored on a 5-point scale from 1 (strongly disagree) to 5 (strongly agree). The Polish version of the inventory was prepared in collaboration with the authors of the original version. The items were translated into Polish and then back-translated into English by a bilingual Polish and English speaker. The authors of the original version accepted the back-translated version. The Polish version of the FFOCI-SF is available from the first author upon request.

Scales for OCPD from the Personality Inventory for DSM-5 (PID-5). The PID-5 (Krueger, Derringer, Markon, Watson, \& Skodol, 2012) is a 220-item selfrated personality trait measure. Each item is rated on a 4-point scale with response categories ranging from very false or often false to very true or often true. The current study only made use of the 32 diagnostic items for obsessive-compulsive personality disorder (i.e., the following scales: Rigid Perfectionism, Perseveration, Intimacy Avoidance, Restricted Affectivity) from the Polish adaptation of PID-5 (Rowiński et al., $2019 b)$. Cronbach's $\alpha$ values were above .75 for all of these PID-5 facet scales.

The Big Five Inventory-2 (BFI-2). The BFI-2 (Soto \& John, 2017) is a 60-item self-reported inventory with a 5-point response scale from 1 (disagree strongly) to 5 (agree strongly). The BFI- 2 consists of 5 domains and 15 facet scales, with three facets per domain. In this study we used scores from five domains and the Cronbach's $\alpha$ values were above .79 for all BFI-2 domain scales.

\section{PARTICIPANTS}

The sample consisted of 328 Polish participants (200 females; $61 \%)$ aged 18 to $75(M=39.79, S D=12.11)$. The sample comprised high school students (14.9\%), students from universities in Warsaw (38.1\%), as well non-students. More than one-third of the sample had a master's degree (36.9\%) and over half of the sample reported having a permanent job (57.9\%) while $11.3 \%$ reported having a part-time job. Further, $6.7 \%$ of the sample reported being retired and $6.4 \%$ indicated they were unemployed. People living in cities with over 100,000 inhabitants made up $41.5 \%$ of participants, people living in towns with 50,000-100,000 inhabitants made up $10.7 \%$ of participants, people living in towns of up to 50000 inhabitants made up $21 \%$ of participants, and people living in villages made up 25.9\% of participants.

Data were collected by students and assistants who were familiar with the data collection protocols. Each of them administered the self-reported paperand-pencil surveys to approximately 4-6 respondents (student's distant relatives, friends or acquaintances). The procedure was voluntary and anonymous. Participants did not receive any remuneration.

\section{RESULTS}

\section{DESCRIPTIVE STATISTICS OF FFOCI-SF}

Table 3 presents the descriptive statistics of each FFOCI-SF scale: mean, standard deviation, skewness
The Polish adaptation of the FFOCI-SF 
and kurtosis. Means of the individual facets of OCPD ranged from 2.06 (Detached coldness) to 3.44 (Perfectionism). Skewness and kurtosis ranged from -1.00 to 1.00 , indicative of a scale distribution close to normal.

\section{INTERNAL CONSISTENCY OF FFOCI-SF SCALES}

The Cronbach's $\alpha$ coefficients for each scale are presented in Table 3. Nearly all of the coefficients can be considered satisfactory with the exception of the Constricted, Detached Coldness and Risk-aversion scales. It is worth noting that the Cronbach's $\alpha$ for Detached Coldness and Risk-aversion became a little higher after removing one recoded item (.62 and .61 respectively). All of the scales related to the Conscientiousness FFM domain have satisfactory coefficients, which is important because an extreme level of Conscientiousness is an important component of an OCPD diagnosis.

\section{FACTOR VALIDITY OF FFOCI-SF}

To verify the factorial structure of the FFOCI-SF, a categorical confirmatory factor analysis was conducted with WLSMV as the estimator. The fit indices are as follows: $\chi^{2}=1999, d f=1014, \mathrm{CFI}=.893$, RMSEA $=.054(.051-.058)$. Two pairs of variables (1) C1 (Perfectionism) and C2 (Fastidiousness), and C4 (Workaholism) and C5 (Doggedness) - are not possible to differentiate and the program generated a message about a non-positive definite matrix at this point. We reran the categorical confirmatory factor analysis with the unified two pairs of variables $(\mathrm{C} 1$ with $\mathrm{C} 2$ and $\mathrm{C} 4$ with $\mathrm{C} 5$ ) and the model fit indices were as follows: $\chi^{2}=2113.9, d f=1035$, RMSEA $=.056$ $(.053-.060), \mathrm{CFI}=.883$, WRMR $=1.483$. We concluded that the structure of 12 facets is problematic as some facets are very closely related and not possible to differentiate. Thus we did the next step and explored the structure of 12 FFOCI-SF scales.

\section{STRUCTURE OF THE FFOCI-SF SCALES}

In order to more deeply explore the structure of the facets we followed the top down procedure proposed by Goldberg (2006). First, we ran an exploratory factor analysis on 12 scales (with principal axis factoring and varimax rotation). The eigenvalues (>1) suggested a four-factor solution. The first factor consists of Doggedness (C5), Workaholism (C4), Punctiliousness (C3) and Perfectionism (C1). Ruminative Deliberation (C6), Excessive Worry (N1) load onto the second factor and Fastidiousness (C2) loads on the first and the second factor. The third factor is built in the majority by Risk-Aversion (E5) and Inflexible (O4) whereas Constricted (O3) and Detached Coldness (E1) are particularly important in the fourth factor. The factor loadings are presented in Table 4.

Following Goldberg's (2006) procedure we also ran an exploratory factor analysis with one-, two-, and three-factor solutions. Next, factor scores from the single-factor model were correlated with factor scores from the two-factor model and then the factor scores from the two-factor model were correlated with factor scores from the three-factor model. Finally, factor scores from the three-factor mode were cor-

Table 3

Descriptive statistics of the Polish adaption of the FFOCI-SF scales

\begin{tabular}{lccccc}
\hline & $M$ & $S D$ & Skewness & Kurtosis & Cronbach's $\alpha$ \\
\hline C1/Perfectionism & 3.44 & 0.71 & -.27 & -.17 & .61 \\
C2/Fastidiousness & 2.89 & 0.83 & .14 & -.14 & .73 \\
C3/Punctiliousness & 3.12 & 0.75 & .08 & -.22 & .64 \\
C4/Workaholism & 2.66 & 0.85 & .20 & -.29 & .76 \\
C5/Doggedness & 3.04 & 0.88 & .04 & -.60 & .82 \\
C6/Ruminative Deliberation & 3.15 & 0.80 & .05 & -.12 & .77 \\
O3/Constricted & 2.38 & 0.68 & .05 & -.34 & .54 \\
O4/Inflexible & 2.66 & 0.74 & .34 & .35 & .68 \\
O6/Dogmatism & 3.15 & 0.79 & .13 & -.43 & .65 \\
E1/Detached Coldness & 2.06 & 0.65 & .32 & -.32 & .58 \\
E5/Risk-Aversion & 3.38 & 0.70 & -.02 & -.06 & .58 \\
N1/Excessive Worry & 3.33 & 0.93 & -.08 & -.77 & .85 \\
\hline
\end{tabular}


Table 4

Factor loadings of the FFOCI-SF scales on the higher order factors obtained in an exploratory factor analysis

\begin{tabular}{|c|c|c|c|c|}
\hline & \multicolumn{4}{|c|}{ Factor } \\
\hline & 1 & 2 & 3 & 4 \\
\hline C5/Doggedness & .83 & .17 & & \\
\hline C4/Workaholism & .71 & .12 & & .14 \\
\hline C3/Punctiliousness & .70 & .20 & .34 & \\
\hline C1/Perfectionism & .70 & .19 & & \\
\hline C2/Fastidiousness & .64 & .55 & & \\
\hline C6/Ruminative Deliberation & .40 & .72 & .15 & \\
\hline N1/Excessive Worry & .11 & .61 & .17 & \\
\hline E5/Risk-Aversion & & .16 & .71 & \\
\hline O4/Inflexible & .12 & .26 & .64 & .30 \\
\hline O6/Dogmatism & .36 & & .39 & .16 \\
\hline O3/Constricted & & & .15 & .80 \\
\hline E1/Detached Coldness & & & & .65 \\
\hline
\end{tabular}

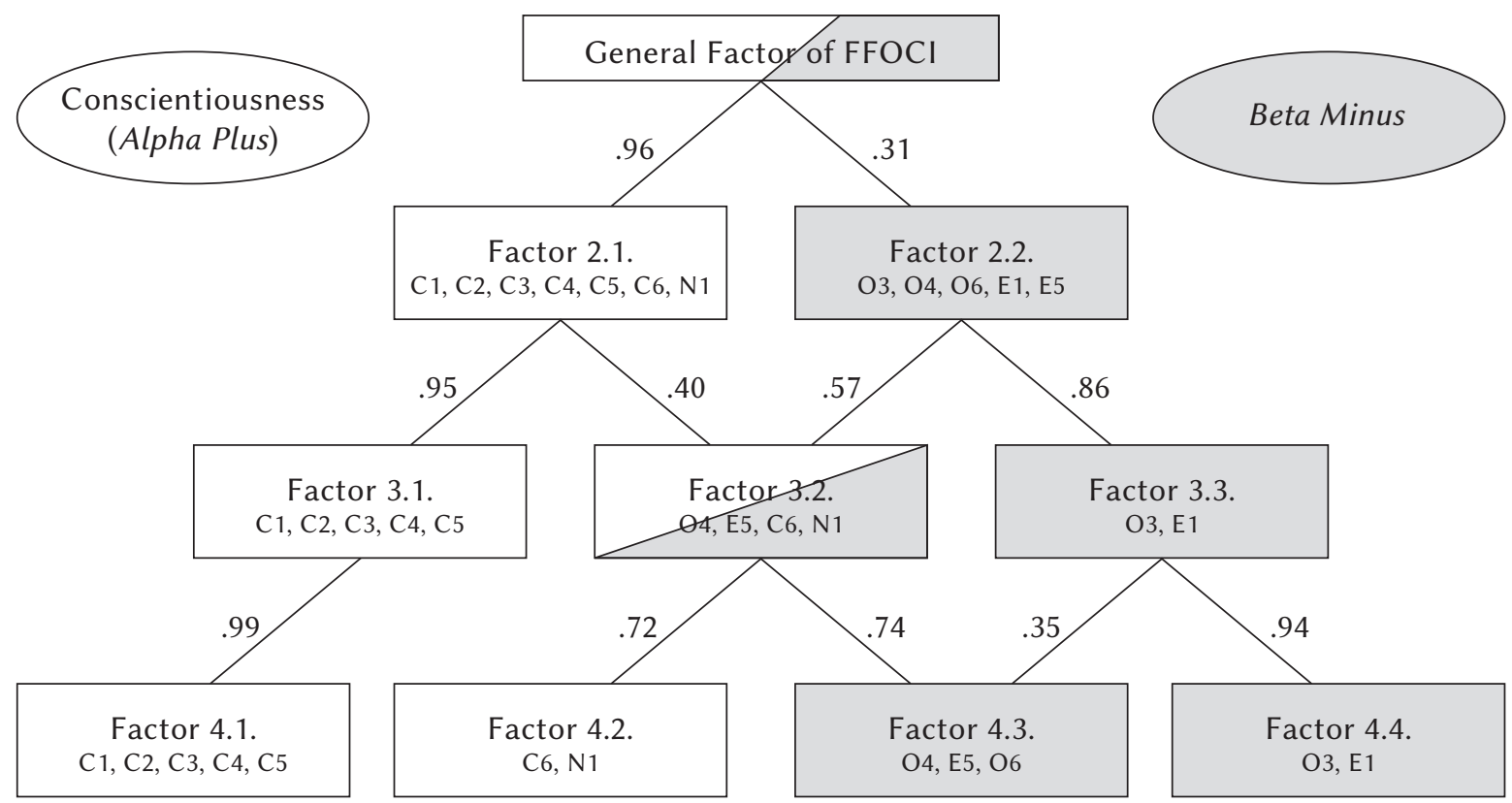

Figure 1. The hierarchical structure of the 12 scales from the Five-Factor Obsessive-Compulsive Inventory Short Form.

related with the scores from the four-factor model. The results are presented in Figure 1.

Figure 1 shows the hierarchical structure of the 12 FFOCI-SF scales from four factors to the one general factor obtained in the exploratory factor analysis. According to our expectations, the two-factor solution produced factors similar to the personality metatraits. The first higher-order factor consisted of all the high Conscientiousness scales (and one Neu- roticism scale), similar to the positive pole of Alpha/ Stability (DeYoung, 2015; Cieciuch \& Strus, 2017) or to the Alpha-Plus metatrait in the CPM (Strus et al., 2014). The second higher-order factor consisted of facets representing low Openness and low Extraversion, similar to the negative pole of Beta/Plasticity (DeYoung, 2015; Cieciuch \& Strus, 2017) or to the Beta-Minus metatrait in the CPM (Strus et al., 2014). Of the two factors, the first factor (6 Conscientiousness,
The Polish adaptation of the FFOCI-SF 
Marcin Kłosowski, Jan Cieciuch, Włodzimierz Strus
1 Neuroticism) loads more strongly onto the general factor. This indicates that the OCPD as measured by the FFOCI-SF can be characterized as mostly high Consciousness (as an aspect of Alpha-Plus) blended with BetaMinus.

\section{CRITERION VALIDITY OF FFOCI-SF - CORRELATION WITH BFI-2 AND PID-5}

Table 5 presents the correlations between the FFOCI facets, Big Five domains and the maladaptive facets from PID-5 used to indicate OCPD.

Our results confirmed our expectations regarding the direction of almost all correlations. Regarding the magnitude of the correlations, all of the Conscientiousness scales from the FFOCI-SF had higher correlations with the BFI-2 Conscientiousness scales than with other domain scales. The highest correlation was found between the FFOCI-SF Doggedness scale (C5) and the BFI-2 Conscientiousness domain. The FFOCI-SF scales for Openness (O3 and O4) correlated highly both with Openness and Extraversion from the BFI-2 and similarly FFOCI-SF Extraversion (E1 and E5) correlated highly both with Extraversion and Openness from the BFI-2. The Neuroticism facet (N1) correlated the most strongly with Neuroticism from the Big Five. Two facets (O3 - Constricted and E1 - Detached Coldness) were more highly correlated with Agreeableness from the Big Five than with the expected scales. Overall, however, the correlations are generally in accordance with our expectations.

Regarding the PID-5, the most significant relations appeared between the Conscientiousness scales and Rigid perfectionism. Consistent with our expectations, Perseveration correlated most strongly with Neuroticism (N1) from the FFOCI-SF. Interestingly, the highest correlate of both Intimacy Avoidance and Restricted Affectivity was Constricted (O3) followed by Detached Coldness (E1), although we had expected the highest correlations to be with Detached Coldness (E1). Therefore, regarding Intimacy Avoidance and Restricted Affectivity (both expected to correlate with Extraversion facets), one can notice similar observation as in the case for correlations between FFOCI-SF and BFI-2: a similar pattern of correlations with Openness and Extraversion facets. 


\section{DISCUSSION}

The main goal of the current study was to present the psychometric characteristics of the Polish adaptation of the FFOCI-SF - a questionnaire created for assessing OCPD. The diagnosis of OCPD is based on the trait approach and in particular on the FFM.

Coefficients of internal consistency (as an approximation of reliability) were acceptable in most scales but with the exception of Detached Coldness and Risk Aversion in which recoded items were problematic. Factor validity of the FFOCI-SF showed that the factor structure is problematic as some facets are not possible to differentiate. The external validity of the Polish adaptation of the FFOCI-SF was generally consistent with our expectations. The vast majority of the FFOCI-SF scales correlate with expected facets of the BFI-2 and PID-5. In particular, all of the FFOCI-SF Conscientiousness scales (i.e., Perfectionism, Fastidiousness, Punctiliousness, Workaholism, Doggedness, Ruminative Deliberation and Detached Coldness) were most strongly correlated with the Conscientiousness from the BFI-2 and PID-5. These findings are consistent with external validity findings of the original version of the FFOCI-SF: convergent validity of the FFOCI-SF subscales with OCPD and related measures were strongest in the Conscientiousness domain (Griffin et al., 2018). It was also the case with the full version of the FFOCI (Crego et al., 2014). Scales connected to Conscientiousness (C1-C6) constitute the core of the FFOCI because according to the DSM-5 an extreme level of Conscientiousness is required to diagnose OCPD.

In terms of the higher-order factors of personality (metatraits), one of two higher-order factors of OCPD was analogous with Alpha/Stability and the second to the negative pole of Beta/Plasticity (consisting of low openness and low extraversion). Therefore, we can generally characterize OCPD as very stable (motivationally), conscientious, although non-plastic (rigid), and anxious personality. This configuration of higher-order personality factors (Alpha-Plus and Beta-Minus) corresponds to Delta/ Self-Restraint - another metatrait distinguished within the CPM (Strus et al., 2014; Strus \& Cieciuch, 2017). As a result, we can conclude that at the most general level OCPD corresponds to personality characteristics such as reduced emotionality (both negative and positive), high behavior control, a tendency to adjust oneself, conformism and conventionality (Strus \& Cieciuch, 2017).

Overall, our results suggest that the FFOCI-SF is a valid and reliable measure for scientific purposes. However, our research was conducted in the general population, and in order to use the FFOCI-SF in a diagnosis further research is needed using clinical samples. Currently we can recommend using the Polish adaptation of the FFOCI-SF only for scientific research, especially in clinical groups, in order to further test for the structure and reliability of the scales.

\section{ACKNOWLEDGMENTS}

The work was supported by Grants 2014/14/M/HS6/ 00919 from the National Science Centre, Poland.

\section{RefERENCES}

American Psychiatric Association (2000). Diagnostic and statistical manual of mental disorders (4th ed.). Washington, DC: American Psychiatric Publishing. American Psychiatric Association (2013). Diagnostic and statistical manual of mental disorders (5th ed.). Arlington, VA: American Psychiatric Publishing.

Baer, L. (1994). Factor analysis of symptom subtypes of obsessive-compulsive personality disorder and their relationship to personality and tic disorders. Journal of Clinical Psychiatry, 55, 18-23.

Cain, N. M., Ansell, E. B., Simpson, H. B., \& Pinto, A. (2015). Interpersonal functioning in obsessivecompulsive personality disorder. Journal of Personality Assessment, 97, 90-99. https://doi.org/10. 1080/00223891.2014.934376

Cieciuch, J., \& Strus, W. (2017). The Two-Factor Model of personality. In V. Zeigler-Hill \& T. Shackelford (Eds.), Encyclopedia of Personality and Individual Differences (pp. 1-16). Basel: Springer International Publishing AG. https://doi.org/10.1007/9783-319-28099-8_2129-1

Coid, J., Yang, M., Tyrer, P., Roberts, A., \& Ullrich, S. (2006). Prevalence and correlates of personality disorder in Great Britain. British Journal of Psychiatry, 188, 423-431. https://doi.org/10.1192/ bjp. 188.5 .423

Colman, A. M. (2009). Stownik psychologii [Dictionary of psychology]. Warszawa: PWN.

Costa, P., Samuels, J., Bagby, M., Daffin, L., \& Norton, H. (2005) Obsessive-compulsive personality disorder: a review. In M. Maj, H. S. Akiskal, J. E. Mezzich, \& A. Okasha (Eds.), Personality Disorders (pp. 405-477). New York: Wiley \& Sons. https:// doi.org/10.1002/0470090383.ch6

Crego, C., Samuel, D. B., \& Widiger, T. A. (2014). The FFOCl and other measures and models of OCPD. Assessment, 22, 135-151. https://doi. org/10.1177/1073191114539382

Decuyper, M., De Pauw, S., De Fruyt, F., De Bolle, M., \& De Clercq, B. J. (2009). A meta-analysis of psychopathy-, antisocial PD- and FFM associations. European Journal of Personality, 23, 531-565. https:// doi.org/10.1002/per.729

DeYoung, C. G. (2015). Cybernetic Big Five theory. Journal of Research in Personality, 56, 33-58. https://doi. org/10.1016/j.jrp.2014.07.004
The Polish adaptation of the FFOCI-SF 
Fox, D. (2013). The Clinician's Guide to the Diagnosis and Treatment of Personality Disorders. Eau Claire, WI: PESI Publishing \& Media.

Freud, S. (1959). Character and anal erotism. In J. Strachey (Ed. \& Trans.), The standard edition of the complete psychological works of Sigmund Freud (Vol. 9, pp. 169-175). London: Hogarth Press (Original work published 1908).

Glover, N., Miller, J. D., Lynam, D. R., Crego, C., \& Widiger, T. A. (2012). The Five-Factor Narcissism
Marcin Kłosowski, Jan Cieciuch, Włodzimierz Strus Inventory: A Five-Factor Measure of Narcissistic Personality Traits. Journal of Personality Assessment, 94, 500-512. https://doi.org/10.1080/002238 91.2012.670680

Goldberg, L. R. (2006). Doing it all Bass-Ackwards: The development of hierarchical factor structures from the top down. Journal of Research in Personality, 40, 347-358. http://dx.doi.org/10.1016/j. jrp.2006.01.001

Griffin, S. A., Suzuki, T., Lynam, D. R., Crego, C., Widiger, T. A., Miller, J. D., \& Samuel, D. B. (2018). Development and Examination of the Five-Factor Obsessive-Compulsive Inventory-Short Form. Assessment, 25, 56-68. https://doi.org/10.1177/1073191116643818

Grilo, C. M. (2004). Factor structure of DSM-IV criteria for obsessive-compulsive personality disorder in patients with binge eating disorder. Acta Psychiatrica Scandinavica, 109, 64-69. https://doi. org/10.1046/j.0001-690X.2003.00223.x

Hummelen, B., Wilberg, T., Pedersen, G., \& Karterud, S. (2008). The quality of the DSM-IV obsessive-compulsive personality disorder construct as a prototype category. Journal of Nervous \& Mental Disease, 196, 446455. https://doi.org/10.1097/NMD.0b013e3181775a4e

Krueger, R. F., Derringer, J., Markon, K. E., Watson, D., \& Skodol, A. E. (2012). Initial Construction of a Maladaptive Personality Trait Model and Inventory for DSM-5. Psychological Medicine, 42, 18791890. https://doi.org/10.1017/S0033291711002674

Lindal, E., \& Stefansson, J. G. (2009). The prevalence of personality disorders in the Greater-Reykjavik area. Laeknabladid, 95, 179-184.

Livesley, J. W., \& Larstone, R. (2018). Handbook of Personality Disorders: Theory, Research and Treatment (2nd ed.). New York: Guilford Press.

Lynam, D. R., \& Widiger, T. A. (2001). Using the Five factor model to represent the DSM-IV personality disorders: An expert consensus approach. Journal of Abnormal Psychology, 110, 401-412. http:// dx.doi.org/10.1037/0021-843X.110.3.401

Magnavita, J. J. (Ed.). (2004). Handbook of Personality Disorders. Theory and Practice. Hoboken, NJ: John Wiley \& Sons, Inc.

Markon, E., Krueger, R., \& Watson, D. (2005). Delineating the structure of normal and abnormal Personality: An integrative hierarchical approach. Journal of Personality and Social Psychology, 88, 139-157. https:/doi.org/10.1037/0022-3514.88.1.139
Marras, A., Fineberg, N., \& Pallanti, S. (2016). Obsessive compulsive and related disorders: Comparing DSM-5 and ICD-11. CNS Spectrums, 21, 324-333. https://doi.org/10.1017/S1092852916000110

McCrae, R. R., \& Costa, P. T. (2008). The five-factor theory of personality. In O. P. John, R. W. Robins, \& L. A. Pervin (Eds.), Handbook of personality. Theory and research (3rd ed., pp. 159-181). New York: Guilford Press.

Moser, J. S., Slane, J. D., Burt, S. A., \& Klump, K. L. (2012). Etiologic relationships between anxiety and dimensions of maladaptive perfectionism in young adult female twins. Depression and Anxiety, 29, 47-53. https://doi.org/10.1002/Da.20890

Oldham, J. M., Skodol, A. E., \& Bender, D. S. (2014). The American Psychiatric Publishing textbook of personality disorders. Washington, DC: American Psychiatric Publishing.

Rowiński, T., Kowalska-Dąbrowska, M., Strus, W., Cieciuch, J., Czuma, I., Żechowski, C., Markon, K. E., \& Krueger, R. F. (2019a). Measurement of pathological personality traits according to the DSM-5: A Polish adaptation of the PID-5. Part I - theoretical foundations. Psychiatria Polska, 53, 7-22. https:// doi.org/10.12740/PP/OnlineFirst/86477

Rowiński, T., Kowalska-Dąbrowska, M., Strus, W., Cieciuch, J., Czuma, I., Żechowski, C., Markon, K. E., \& Krueger, R. F. (2019b). Measurement of pathological personality traits according to the DSM-5: A Polish adaptation of the PID-5. Part II - empirical results. Psychiatria Polska, 53, 23-48. https://doi. org/10.12740/PP/OnlineFirst/86478

Samuel, D. B., Riddell, A. D. B., Lynam, D. R., Miller, J. D., \& Widiger, T. A. (2012). A five-factor measure of obsessive-compulsive personality traits. Journal of Personality Assessment, 94, 456-465. https://doi.org/10.1080/00223891.2012.677885

Samuel, D. B., \& Widiger, T. A. (2011). Conscientiousness and obsessive-compulsive personality disorder. Personality Disorders: Theory Research and Treatment, 2, 161-174. https://doi.org/10.1037/A0021216

Schneider, B., Wetterling, T., Sargk, D., Schneider, F., Schnabel, A., Maurer, K., \& Fritze, J. (2006). Axis I disorders and personality disorders as risk factors for suicide. European Archives of Psychiatry and Clinical Neuroscience, 256, 17-27. https://doi. org/10.1007/s00406-005-0593-7

Soto, C. J., \& John, O. P. (2017). The next Big Five Inventory (BFI-2): Developing and assessing a hierarchical model with 15 facets to enhance bandwidth, fidelity, and predictive power. Journal of Personality and Social Psychology, 113, 117-143. https://doi.org/10.1037/pspp0000096

Sperry, L. (2016). Handbook of the diagnosis and treatment of DSM-5 personality disorders. New York: Routledge.

Strus, W., \& Cieciuch, J. (2017). Towards a synthesis of personality, temperament, motivation, emotion 
and mental health models within the Circumplex of Personality Metatraits. Journal of Research in Personality, 66, 70-95. https://doi.org/10.1016/j. jrp.2016.12.002

Strus, W., Cieciuch, J., \& Rowiński, T. (2014). The Circumplex of Personality Metatraits: A synthesizing model of personality based on the Big Five. Review of General Psychology, 18, 273-286. https:// doi.org/10.1037/gpr0000017

Strus, W., Rowiński, T., Cieciuch, J., Kowalska-Dąbrowska, M., Czuma, I., \& Żechowski, C. (2017). The Pathological Big Five: An attempt to build a bridge between the psychiatric classification of personality disorders and the trait model of normal personality. Roczniki Psychologiczne, 20, 451-472. https:// doi.org/10.18290/rpsych.2017.20.2-6en

Torgersen, S. (2009). Prevalence, sociodemographics, and functional impairment. In J. M. Oldham, A. E. Skodol, \& D. S. Bender (Eds.), Essentials of personality disorders (pp. 83-102). Washington, DC: American Psychiatric Publishing.

Watson, H. J., Raykos, B. C., Street, H., Fursland, A., \& Nathan, P. R. (2011). Mediators between perfectionism and eating disorder psychopathology: Shape and weight overvaluation and conditional goal-setting. International Journal of Eating Disorders, 44, 142-149. https://doi.org/10.1002/ Eat.20788

Widiger, T. (Ed.). (2012). The Oxford Handbook of Personality Disorders. Oxford, NY: Oxford University Press.

Widiger, T. A., \& Simonsen, E. (2005). Alternative dimensional models of personality disorder: Finding a common ground. Journal of Personality Disorders, 19, 110-130. https://doi.org/10.1521/ pedi.19.2.110.62628

Widiger, T. A., Trull, T. J., Clarkin, J. F., Sanderson, C., \& Costa, P. T. (2002). A description of DSM-IV personality disorders with the Five-factor model of personality. In P. T. Costa \& T. A. Widiger (Eds.), Personality disorders and the Five-factor model of personality (2nd ed., pp. 89-99). Washington, DC: American Psychological Association. http:// dx.doi.org/10.1037/10423-006

Zawadzki, B. (2016). Gamma i Delta w ujęciu Kołowego Modelu Metacech Osobowości a przekonania w zaburzeniach osobowości [Gamma and Delta in the Circumplex of Personality Metatraits and beliefs in personality disorders]. In A. Rynkiewicz, K. S. Jankowski, \& W. Oniszczenko (Eds.), Wybrane metody i paradygmaty badawcze w psychologii [Selected methods and paradigms of research in psychology] (pp. 203-220). Warszawa: WN Scholar.

Zawadzki, B. (2017). The location of personality disorders in the Circumplex of Personality Metatraits. Roczniki Psychologiczne, 20, 473-512. https://doi. org/10.18290/rpsych.2017.20.2-7en 